\title{
Improving Efficiency of Underground Heat Storage Systems
}

\author{
Derek B. Apel ${ }^{1 *}$ and Babak Nikbakhdan ${ }^{2}$ \\ ${ }^{1}$ Professor, Department of Civil Engineering, University of Alberta \\ ${ }^{2}$ Construction Project Manager, Brontes Homes, Vancouver, Canada \\ "CORRESPONDING AUTHOR'S E-MAIL: DEREK.APEL@UALBERTA.CA
}

\begin{abstract}
Underground thermal energy storage (UTES) systems are very popular in Europe and are gaining popularity in North America. The first large-scale solar borehole thermal energy storage (UTES) system in Canada has been implemented in the town of Okotoks (McClenahan D, 2006). The second UTES project in Alberta is located in the community of Southwoods in Edmonton (Kantrowitz T. et al., 2013), which proposes to use natural gas cogenerators to generate electricity and heat during the winter to improve electricity generation efficiency and hence reduce overall energy costs. During the generation of electricity, unused heat can be collected and used to heat space and water for domestic use. During the summer, the electrical output from cogeneration exceeds demand, resulting in a seasonal and annual thermal imbalance which UTES can control through the transfer and storage of the excess heat to a UTES system. Most soils in the Edmonton region consist of sandy clays with high moisture content and high thermoconductivity. Thus, storing heat in such soils would be inefficient since most of the heat would escape before it could be used for heating purposes. However, if such soils could be modified to become good insulators via innovations in jet grouting and soilcrete technologies, UTES systems could become more prevalent as a renewable energy source in areas with highly thermoconductive soils. This paper proposes to develop the jet grouting and soilcrete theory and conceptual models required to create an insulated enclosure around UTES systems in highly thermo-conductive soils.
\end{abstract}

KEYWORDS

Underground thermal energy storage (UTES), heat, jet grouting, insulation, thermo-conductivity.

\section{INTRODUCTION}

In developed economies, buildings are the most important energy consumers. They approximately consume forty percent of energy and greenhouse gas emissions which fifty-five percent of building energy goes to the heating and cooling. Thermal Energy Storage can be a solution for the demand with simultaneously reducing of Green House Gas emissions. The Thermal Energy Storage system stores the energy which can be either heat or cold in the ground to be used at later time. One of most common types of the Thermal Energy Storage systems is Seasonal Thermal Energy System which store a large volume of the energy to meet the seasonal load (Gaine and Duffy 2010). The Seasonal Thermal Energy Systems usually store the energy underground and are known as Underground Thermal Energy Storage (UTES). Borehole Thermal Energy Storage (BTES) is a common practice of the Underground Thermal Energy Storage and is a closed loop system which includes many vertical boreholes placed 50 to 200 meters below the ground. In this method the ground itself is the storage medium. Energy is carried out from energy source into the ground using a single or multiple U-tubes (Figure1) which are inserted into the boreholes to deliver/absorb the heat using fluids into/from the ground. 
The best ground conditions for BTES methods are high thermal conductivity with low groundwater flow (Kun Sang Lee, 2006).

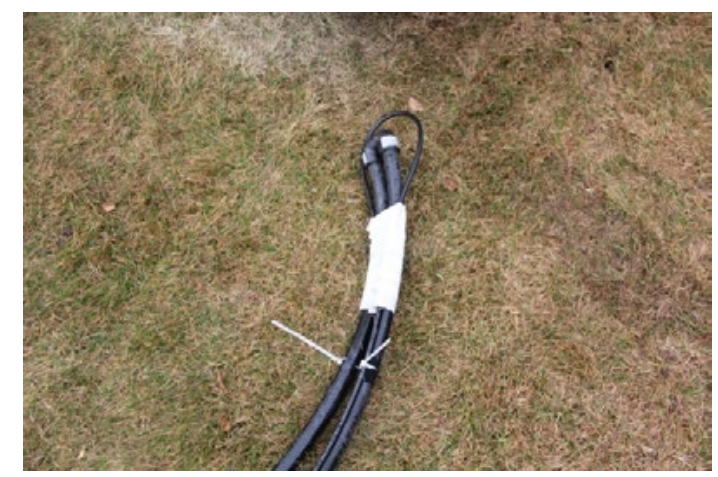

Figure 1. U-tubes before insertion into the borehole.

The performance of the BTES systems are dependent to various operational and geometrical parameters such as operation schedules, injection temperature, injection-production rate, geometrical configuration of borehole, permeability of ground, and thermal properties of the ground (Kun Sang Lee, 2010). Many soils consist of sandy clays with high moisture content and high thermo-conductivity. Thus, storing heat in such soils would be inefficient since most of the heat would escape before it could be used for heating purposes. However, if such soils could be modified to become good insulators via innovations in jet grouting and soilcrete technologies, UTES systems could become more prevalent as a renewable energy source in areas with highly thermo-conductive soils. This research proposes to develop the jet grouting and soilcrete theory and conceptual models required to create an insulated enclosure around UTES systems in highly thermo-conductive soils (Figure 2).

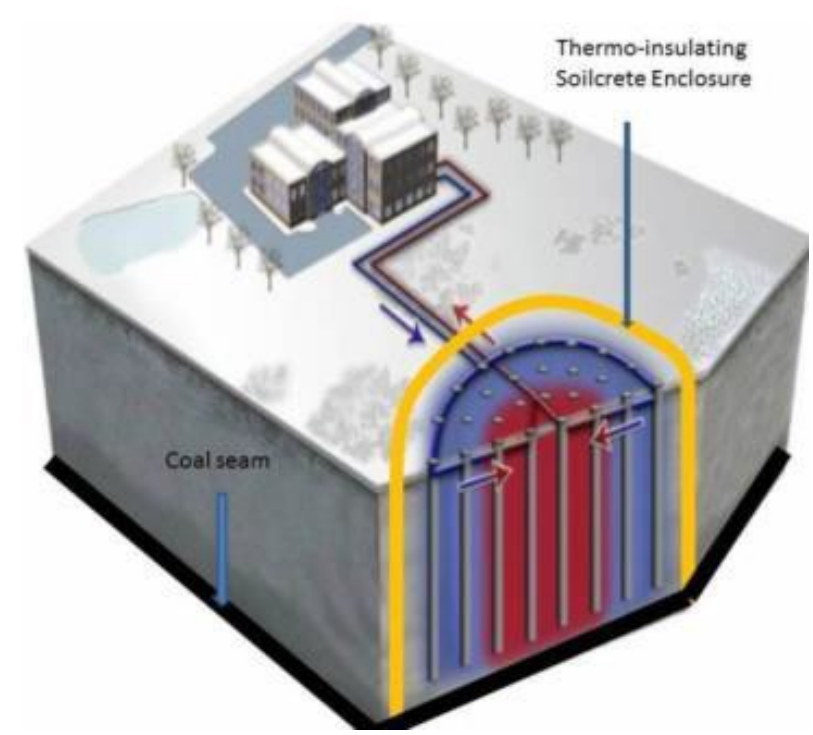

Figure 2. Conceptual view of the UTES system with a thermo-insulating barrier. 


\section{METHODS}

In the current research study thermal properties of the ground have been investigated to increase the performance of the UTES systems. To verify and validate the success of the proposed design, thermal-insulating grout was developed in the laboratory using three different aggregates of water, cement, and perlite (ELP) material (Bolen, W. P. 2004). Then, based on the theoretical definition of the jet grouting process, soilcrete specimens were obtained by jet grouting the grout into prepared tank with soil obtained from a construction site in Edmonton. After 28 days the soilcrete samples were cored drilled from the jet grouting tank. Then the thermal properties of the soilcrete were compared with the thermal properties of the used soil. The Thermal Constants Analyzer TPS 1500 ( $\mathrm{Liu}$ at a 1., 2014 ) was used to determine the thermal properties of soilcrete specimens.

The results were verified based on the literature values and findings. After a suitable thermal- insulating grout mixture was developed and the manufacturing laboratory jet grouting setup completed, an actual jet grouting test was performed on the reconstructed in-situ soil formation in the jet grouting tank. The optimal jet grouting operational parameters were used to create the actual thermal-insulating soilcrete. Also, the capability of the manufactured jet grouting setup and actual laboratory jet grouting experiment results were verified with welldocumented literature about jet grouting projects (Nikbahdan, 2014).

The laboratory tests were conducted at the rock mechanics laboratory at the University of Alberta. Since best way to evaluate jet grouting performance and soilcrete properties is to conduct a laboratory experiment simulation of jet grouting in a particular soil condition with actual jet grouting parameters and equipment (Ji 2008). However, actual jet grouting equipment is too big to be used in a laboratory. A decision was made for this project to design and build laboratory jet grouting equipment that would have almost the same ability as actual field equipment but with a reduced footprint and cost. To the author's knowledge, to date, no laboratory setup is available for evaluating double and triple fluid jet grouting, which are the most complicated and efficient jet grouting methods. Constructing a complete physical model of the jet grouting system simulates the entire process in a laboratory environment where all parameters can be taken into account together.

The jet grouting laboratory setup at the UofA contains eight main components (Figure 3): a high-pressure pumping plant, grout mixer plant, water and grout swivel and rotary union, jetting monitor and nozzles, high-pressure hoses, rotating and withdrawal systems, relief valve, and mixing tank. The main components of the water jet application are the water storage tank, pump, delivery pipe, control valve, relief valve, and nozzles. The water passes through the pump and is pressurized into the delivery pipe and then into the nozzles. The nozzles have a smaller orifice diameter than the pipes; thus the velocity of water is being accelerated to pass the nozzles. At the same time, the control valve controls the amount of water that flows toward the nozzles. The relief valve is designed for safety reasons, to divert extra water to the storage tank to prevent any water build-up. Any water jet application shall be designed based on a particular task. A custom-made jet grouting tank that is 42 inches in diameter and 40 inches high was designed based on the laboratory feasibilities and the nature of jet grouting. Cohesionless soils are easy to cut and erode because they have only moisture as a binder and nothing else. However, clays are difficult to erode because they have cohesion. Clays are generally eroded in chunk pieces, which are larger than the size of a grain of sand. Since uplift velocity is not great enough to exhaust these particles to the ground surface, annulus plugging can occur. To prevent this, casing was modeled on the cap of the tank to accelerate the 
outflow of the spoil material. The casing was connected to the spoil material-collecting drums.Four holes were designed on the perimeter of the tank to allow the entry of compressed air and simplify the procedure to demold the hardened soilcrete after the jet grouting process. After the jet grouting, all of the bolts can be removed from the bottom of the tank. Using the other four chain hooks around the tank, the whole tank can be removed and the hardened soilcrete will be left on the bottom of the tank for further investigation. A control panel was designed to control all jet grouting operational parameters at the same time using all Variable Frequency Drives for the water and grout pump, speed controller for vertical and rotational motions, and mixer motor and emergency stops for each motor.

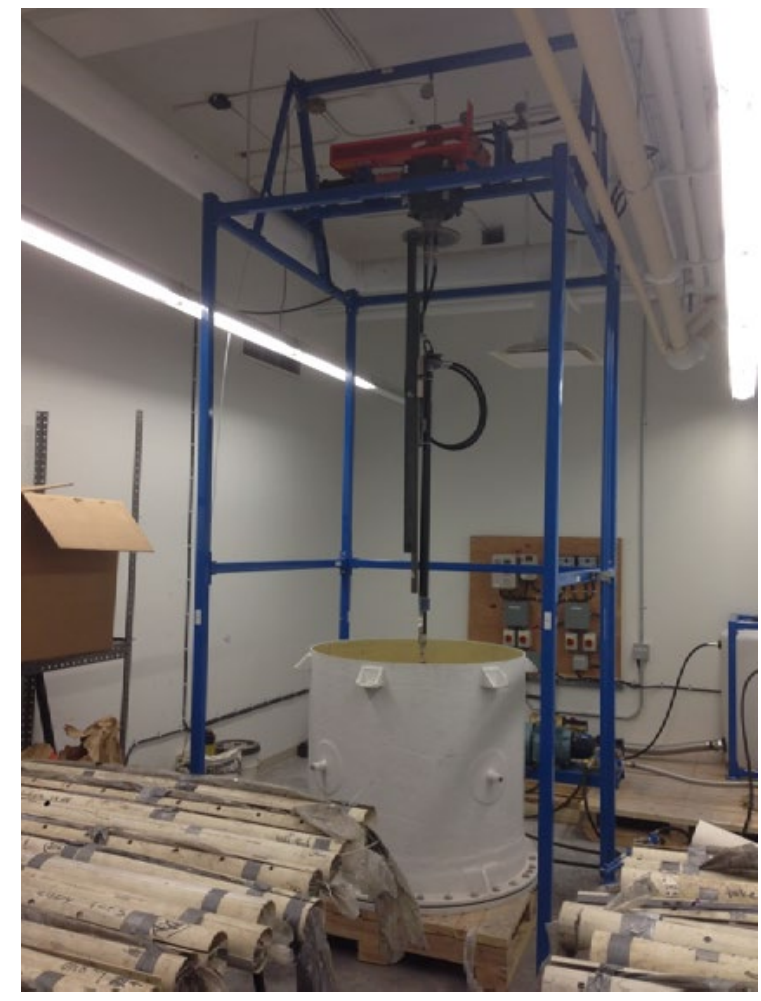

Figure 3. Laboratory jet grouting setup at the UofA

\section{RESULTS AND DISCUSSION}

Figure 4 shows that the thermal conductivity of soilcrete specimens with respect to thermal conductivity of soil was reduced by $56 \%$ and $89 \%$ in wet and dry conditions, respectively (Nikbaktan B., 2015). As discussed earlier, the thermal conductivity is a measure of the material's ability to conduct heat. After the field jet grouting operations, the soil's ability to conduct heat through its structure will reduce by $89 \%$ in the dry condition. This is what happens when the borefield has already been injected with thermal energy. Thermal conductivity in the wet condition is higher than in the dry condition, which is caused by the higher thermal conductivity of water in the wet condition compared to its value of air in the dry condition. 


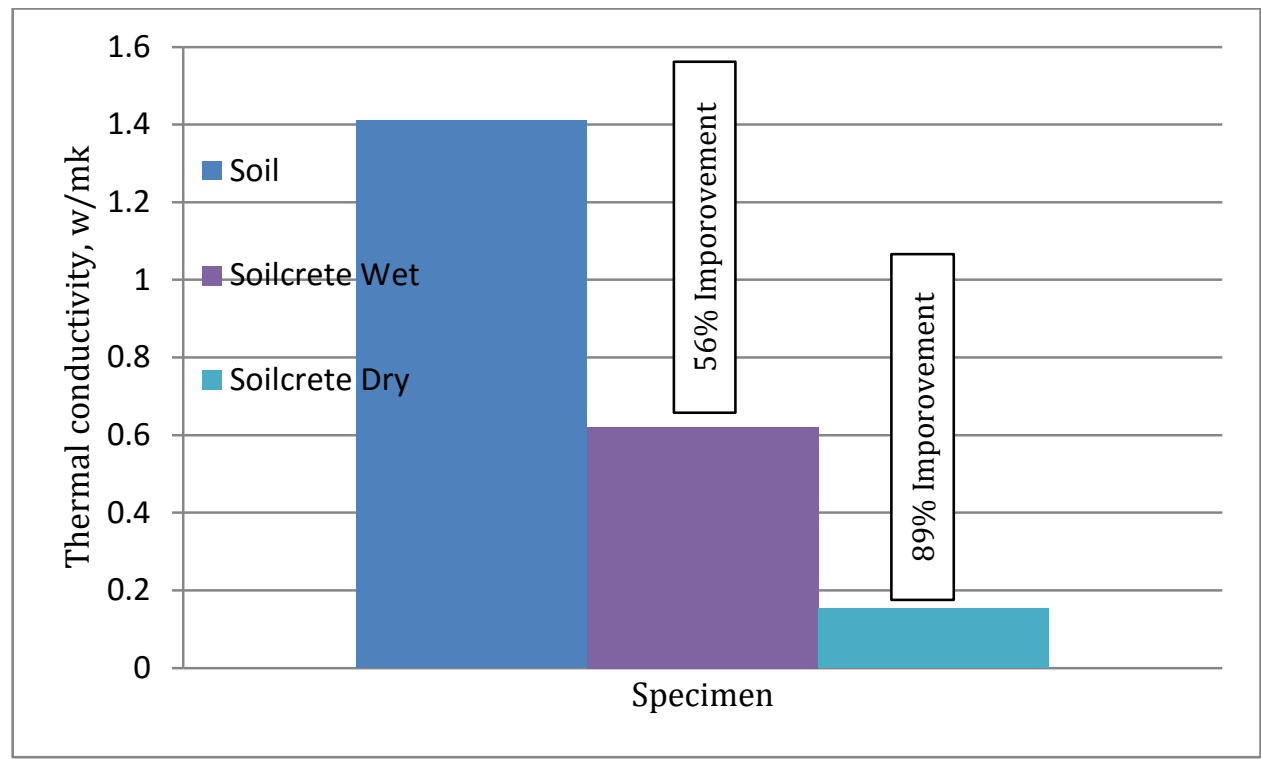

Figure 4. Thermal conductivity of Soil vs Wet and Dry Soilcrete

Thermal diffusivity is defined as a material's ability to adjust its temperature to the surrounding environment. For thermal-insulating purposes, material with low heat diffusivity is preferred. As shown in Figure 5, the thermal diffusivity of soilcrete specimens was reduced $74 \%$ and $86 \%$ with respect to in-situ soil in wet and dry condition, respectively. Theoretically, thermal diffusivity is calculated by dividing thermal conductivity by volumetric heat capacity. The thermal conductivity was reduced more in the dry soilcrete specimens than in the wet ones, suggesting that heat diffusivity is greater in wet than dry conditions

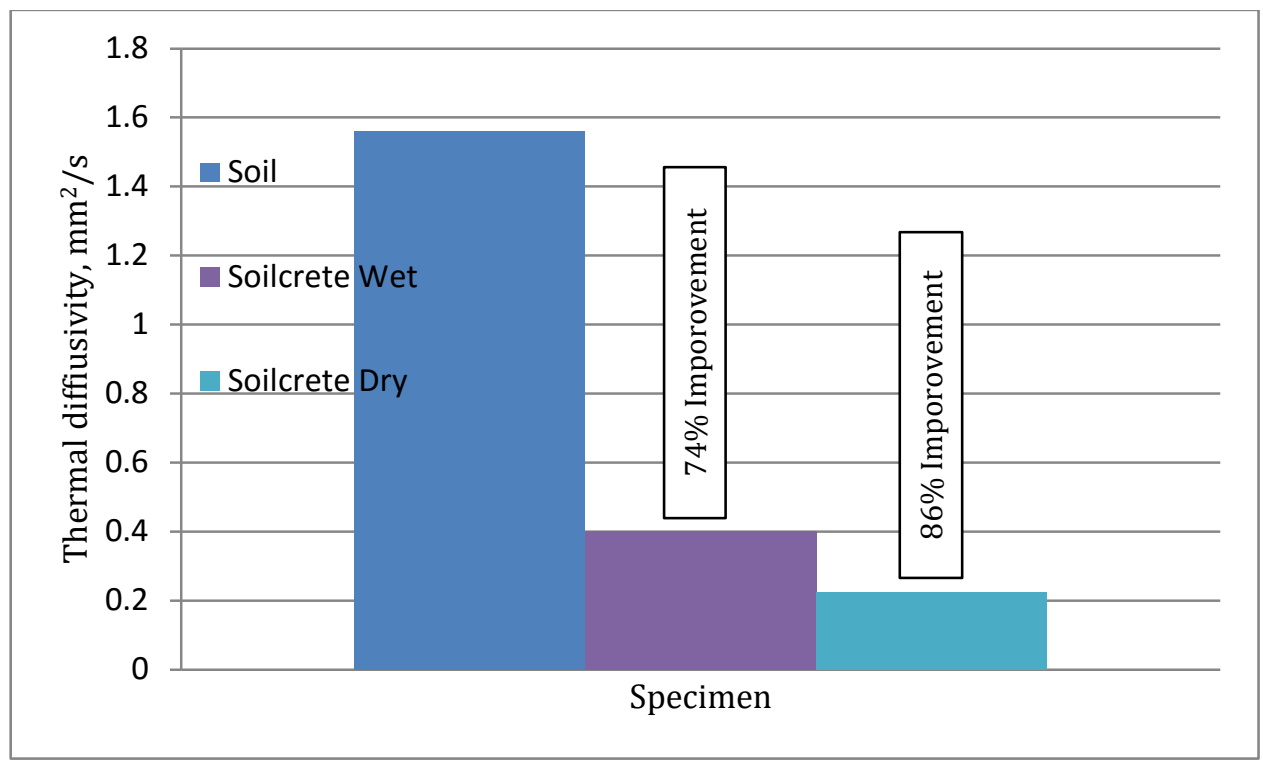

Figure 5. Thermal diffusivity of Soil vs Wet and Dry Soilcrete 


\section{CONCLUSION}

The results of the laboratory tests showed that by mixing the soils with the thermo-insulating grouts using jet grouting technique we can reduce the soil thermal conductivity by up to $89 \%$ and improve soil thermal diffusivity by up to $86 \%$ consequently the performance of the UTES s y ste ms would be improved when such systems will be encapsulated by thermoinsulating soilcrete barrier.

\section{ACKNOWLEDGEMENTS}

Authors would like to thank Mr. Mike Ropelt of GSS Geothermal Ltd. for introducing us into the world of Underground Heat Storage Systems and Mr. Mykola Bilash of John Brooks Ltd for helping us with the design and manufacturing of the laboratory jet grouting setup.

\section{REFERENCES}

Bolen, W. P. 2004. "Perlite." U.S. Geological Survey.

1. Ji, Heng. 2008. "Physical Modelling of Jet Grouting Process." University of Cambridge.

2. Gaine K., Duffy A., a life cycle cost analysis of large-scale thermal storage technologies for buildings using combined heat and power, Zero emission buildings-Proceedings of renewable energy conference, (2010)

3. Kantrowitz T., Bruce Mcfarlane B., Canada's heat pump association congratulates an Alberta integrated energy leader, Canadian GeoExchange Coalition, www.geoexchange.ca, (2012)

4. Kun Sang Lee, simulation on the cyclic operation of an open borehole thermal energy storage system under regional groundwater flow, Geosciences Journal Vol. 14, No. 2, (2010) 217 224

5. Kun Sang Lee, performance of open borehole thermal energy storage system under cyclic flow regime, Geosciences Journal Vol. 12, No. 2 (2008) 169-175

6. McClenahan D., Gusdorf J., Kokko J., Thornton J., Wong B., Okotoks: seasonal storage of solar energy for space heat in a new community, ACEEE Summer Study on Energy Efficiency in Buildings (2006) 11-121 to 11-132

7. Nikbaktan B., 2015, Development of Thermal-Insulating Soilcrete using Laboratory Jet Grouting Setup, PhD Thesis, University of Alberta, pp. 328.

8. Liu, W.V., Apel, D.B., Bindiganavile, V.S., 2014, "Thermal properties of lightweight drymix shotcrete containing expanded perlite aggregate", Journal of Cement \& Concrete Composites, Science Direct, Vol. 53, pp. 44-51 Language: English.

DOI:0.1016/j.cemconcomp.2014.06.003

9. Liu, W. V., Apel, D. B. \& Bindiganavile, V. (2011) Thermal characterization of a lightweight mortar containing expanded perlite for underground insulation. International Journal of Mining and Mineral Engineering, 3, 55

10. Kantrowitz T., Bruce Mcfarlane B., Canada's heat pump association congratulates an Alberta integrated energy leader, Canadian GeoExchange Coalition, www.geoexchange.ca, (2012)

11. Kun Sang Lee, simulation on the cyclic operation of an open borehole thermal energy storage system under regional groundwater flow, Geosciences Journal Vol. 14, No. 2, (2010) $217-224$ 